\title{
Online Establishment Automation System
}

\author{
Prof. B. A. Jadhawar', Ms. D.K. Deshmukh ${ }^{2}$ \\ Assistant Professor, Computer Science and Engineering, DACOE, Karad, India ${ }^{1}$ \\ Student, Computer Science and Engineering, DACOE, Karad, India ${ }^{2}$
}

\begin{abstract}
The existing system is not a complete automated system for that matter their leave management, document management is totally manual and it takes a long time to process a leave request. In the proposed system a leave application has to go through a long chain of official and as a result, several time the competent authorities get manipulated information. The proposed system is used to solve the identified problems. The proposed system will minimize the paperwork. It will help management in decision making as they will get up-to-date report. The aim of this paper is to develop a web based application that can access through internet from anywhere. This Online Establishment Automation system can generate reports for every month and year. The proposed system also provide the facility to manage their profile.
\end{abstract}

Keywords: Automation, Leave, Controlling officer, HoD, paperwork.

\section{INTRODUCTION}

Online Establishment Automation System will develop to upgrade the current leave application and record which is manually processed. The proposed system will minimize the problem currently faced by existing system.

The function of the system is to simplify leave application through online, for improving the mechanism of receiving, approving and rejecting leave application to enable the admin to record inapplicable leave, to generate report of employees in order to be use in evaluating the performance.

\section{PROBLEM DEFINITION}

The "Online Establishment Automation System" is designed to manage the information of employees i.e. employee record such as educational details, profile, leave record etc. This system is time consumable, wastage of paper etc.

\section{LITERATURE REVIEW}

The main objective of this online establishment automation management system is that managing employee details such as employee information, documents, leave details, leave approval, leave cancellation and generating the report for every month and yearly basis.

Managing employee details manually is a time taking process and data is not secured, finding old records are not easy. By considering issues in manual method the online establishment automation system developed to help in document management, information storing, leave balance and in generating leave balance. The existing manual management system is initiated with the submission of a leave application by an employee for leave.
This application is submitted to the controlling officer at least two days head (with exception of casual leave and the quarantine leave) from the date of commencement of the leave applied for.

The controlling officer is responsible for checking out the eligibilities of the employee for the type of leave and he/she has applied for. If the applicant employee is eligible then the controlling officer submits the application to the HoD of the Department. The work of the HoD is the most complicated as employee responsible for the synchronization of the leave.

In case of Earned leave with full pay, Medical leave, Quarantine leave and Casual leave the HoD has the sole authority to approved or refuse the leave.

If the HoD allows the user for leave, employee should inform the principal by submitting a report which will contain the details about the approved leave by the HoD. Then Principal takes their decision and let the HoD know the result by an Officer letter. Then the HoD let know the result to leave applicant employee manually

In the existing system, the user submits their documents such as their Mark sheets, Research papers to the Controlling officer manually. User can also request for documents like Experience Letter, Salary Certificate and Form No.16 to the Controlling officer manually.

Hence for creation of more transparent and accurate leave process, reduce the number of request that controlling officer handle manually. By the online Establishment automation system more no. of the task done automatically by system also the time required for controlling officer to process a leave request can decrease to less than five minute. 
IARJSET

\section{IV.MATERIAL AND METHODOLOGY}

The online establishment automation system consist of the main seven modules which are the Leave management, staff profile, Manage document, Skill inventory, request for experience letter, request for salary certificate, request for form no. 16 .

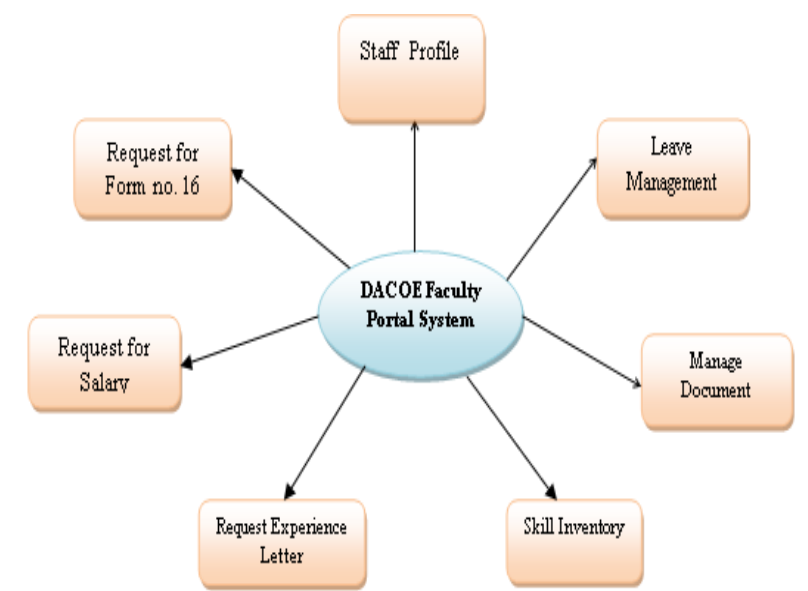

Fig.1. Architecture of the Online Establishment Automation System

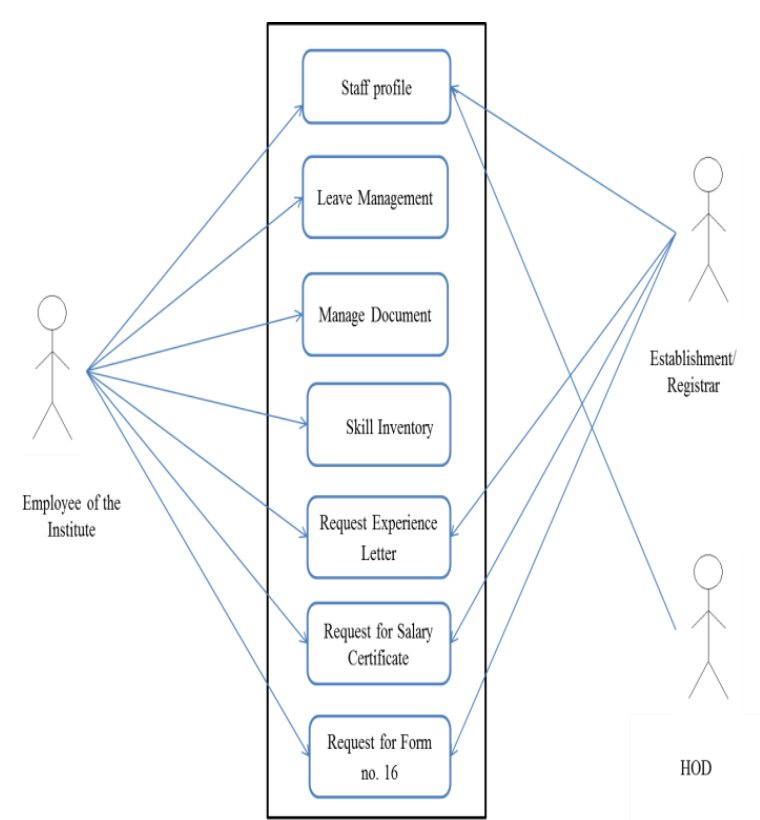

Fig2. Use Case Diagram of Online Establishment Automation System

In this system involved entities are shown in above diagram. Every employee such as principle, HoD, teaching, non-teaching staff are eligible to access the all main seven modules as per their designation.

Only principle has rights to approve the leave of all In this module, faculty can request for salary certificate. employee and see all information also HoD has rights to approve the leave and see all the information of their particular department.
Registrar act as administrator which has rights to create account of the employee, manage leave records of every employee.

Also act on the request of salary certificate, experience letter, Form No.16 as per request.

Role of modules are as follows:

A. STAFF PROFILE:

This module contains another three sub modules. They are as follows:

I. Edit Your Profile:-

It shows profile of particular employee which is login.

II. Create New Staff:-

Only registrar can use this menu to create new account of employee.

III. View All Staff:-

It shows all employee information. It is only accessible to principle and HoD.

\section{B. LEAVE MANAGEMENT:}

This module contains another three sub modules. They are as follows:

\section{Apply For Leave:-}

Any employee of the institute can apply for leave. It contain leave form which includes name of the employee, leave type such as privilege leave, casual leave, sick leave, maternity leave. As per their leave balance available employee can choose type of leave and apply for leave.

\section{Check Leave Status:-}

Employee which is login can check the leave status as approved by HoD and principle.

III. Check Leave Balance:-

Employee can see their available leave. Also principle and HoD are eligible to see all employee leave balance.

\section{MANAGE DOCUMENT:-}

In this module, faculty can upload their documents like mark sheets, research paper, experience data etc. .

\section{MANAGES SKILL INVENTORY:}

In this module, faculty can fill the experience about each subject.

\section{E. REQUEST FOR EXPERIENCE LETTER:}

In this module, faculty can request for experience letter.

\section{F. REQUEST FOR SALARY CERTIFICATE:}

G. REQUEST FOR FORM NO.16:

In this module, faculty can request for salary certificate. 
IARJSET AGTI's Dr. Daulatrao Aher College Engineering, Vidyanagar Extension, Karad

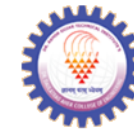

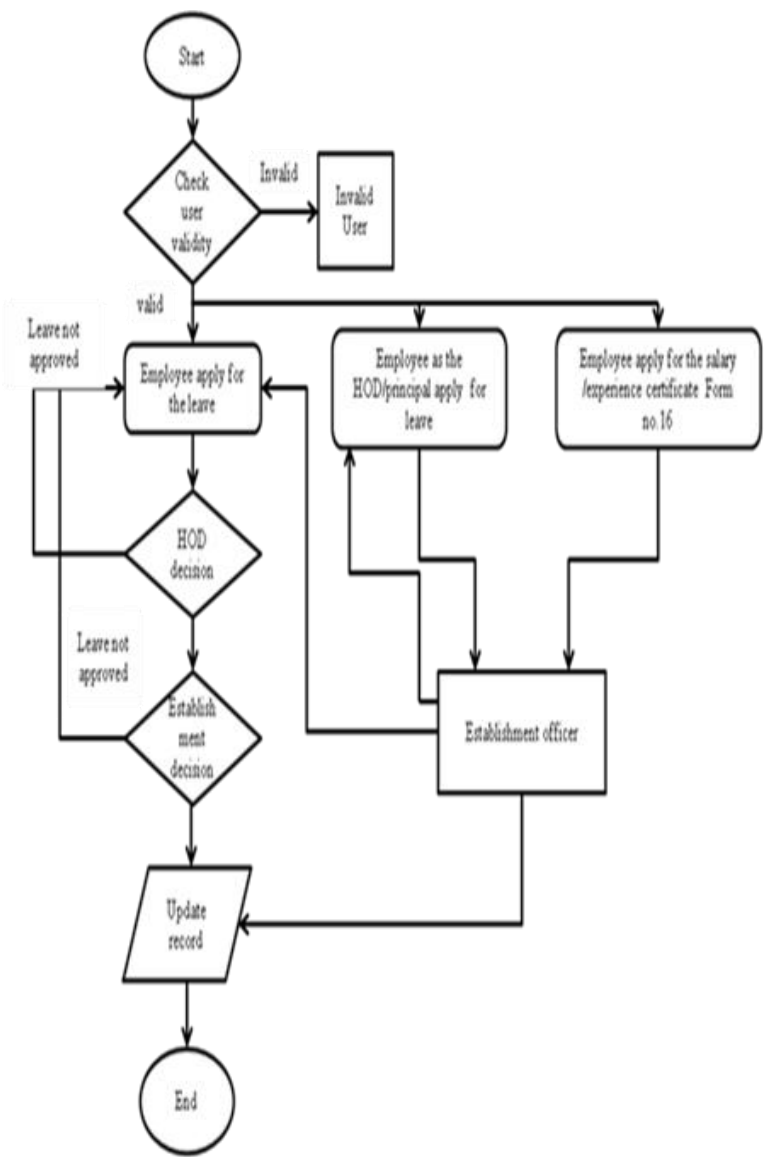

Fig 3 Flow chart of the system

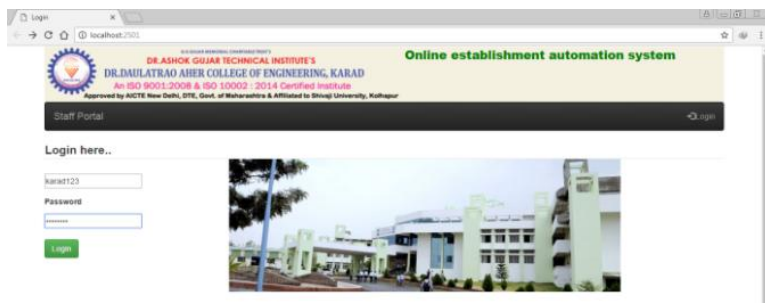

Fig 4. Login Page

Above Fig. shows the login page which will contain Login ID and password window. After user login he/she goes to the home page.

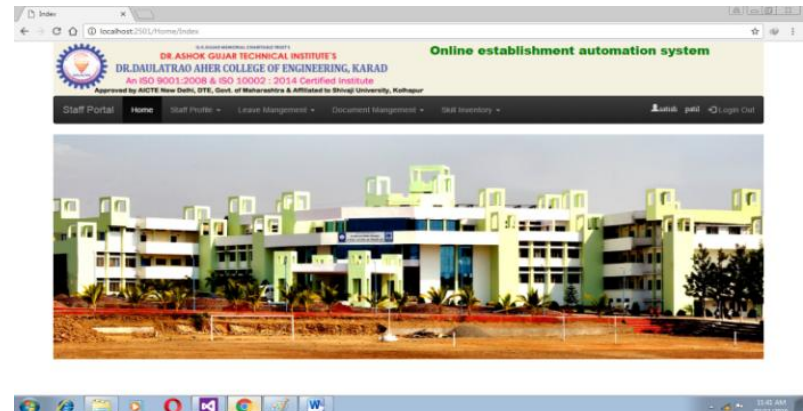

Fig 5. Home Page
Above Fig. shows the home page of the Online Establishment Automation system

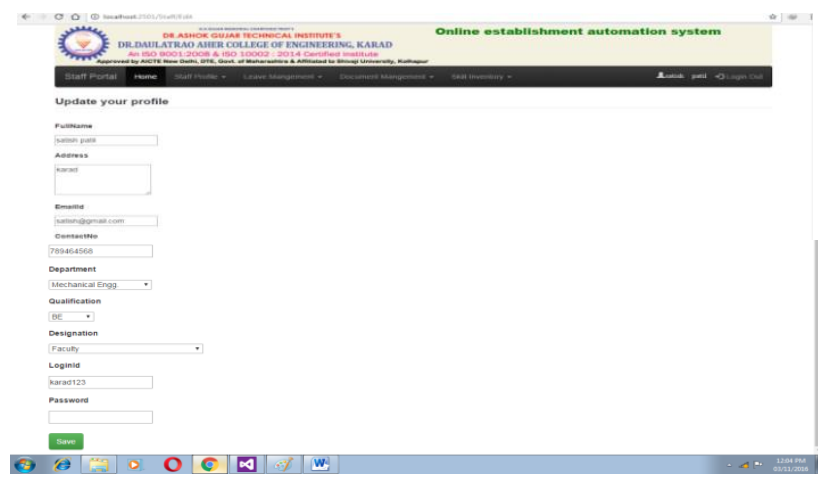

Fig 6.Update Your Profile option

Above Fig. shows that the system will provide the facility to every user that to Update own profile.

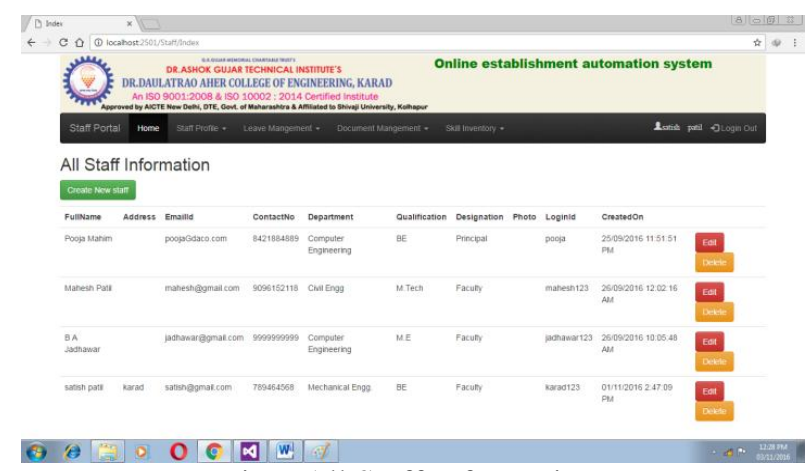

Fig 7.All Staff Information

Fig. shows the all staff information but this option is accessible to only registrar and HoD, Principal.

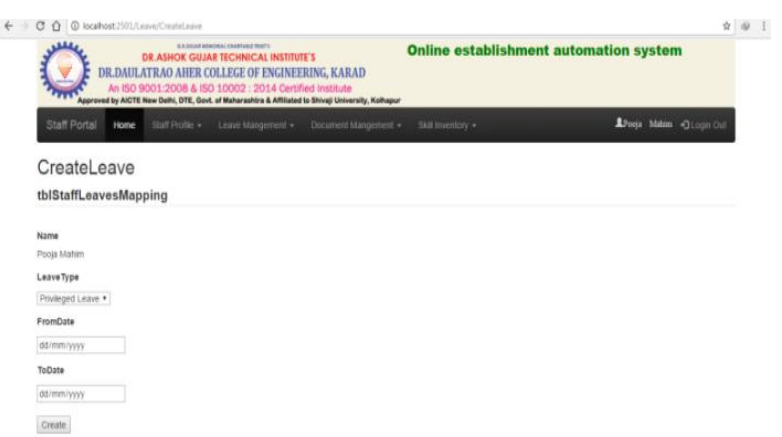

Fig 8. Create Leave

Fig. shows the create leave option, by using it employee can request for the leave.

\section{CONCLUSION}

These projects reduce the paper work and saving time to generate accurate results. The system provides with the best user interface. This system also reduce the office work. These systems make available online leave management, profile management. 
IARJSET

The employees may be applying for leave and request for their documents from their home as well. Moreover, it will ensure less paper works and as a result the whole process will be swift and reliable.

\section{REFERENCES}

1. Software Engineering-roger Pressman

2. System Analysis and Design-Alias M. Awad

3. www.dotnettricks.com

4. www.designbrooklyn.com

5. www.w3schools.com

\section{BIOGRAPHIES}

Prof. Jadhawar B. A. has master degree in Computer Science and Engineering from WCE, Sangli in Shivaji University. She has 9.1 years of experience in teaching field. Currently working as Assistant Professor at DACOE, Karad. Her area of interest is database.

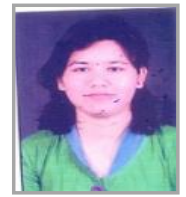

Ms. Deshmukh Dhanashri K. Currently doing Bachelor degree in computer engineering from Shivaji University at DACOE. 